\title{
Societal Factors of Private Tutoring in English: Evidence from Bangladeshi Higher Secondary Students
}

\author{
Monjurul Islam \\ Assistant Professor\& Head of the Department of English \\ Faculty of Humanities and Social Science \\ Pundra University of Science and Technology, Bangladesh
}

$\&$

Ph.D. candidate at Faculty of Education, University of Malaya, Malaysia

Dr. Kazi Enamul Hoque

Senior Lecturer, Faculty of Education, University of Malaya, Malaysia.

Prof. Dr. Moses Samuel

School of Education, Taylor's University, Malaysia

Mohammed Shamsul Hoque

Associate Professor

Department of English

Daffodil International University (DIU), Bangladesh

Received: Sep. 20, 2017 Accepted: Nov. 26, 2018 Published: November 26, 2018

doi:10.5296/jse.v8i4.11890 URL: https://doi.org/10.5296/jse.v8i4.11890

\begin{abstract}
This study used the phenomenological qualitative research design to provide insights into the lived experiences of nine Bangladeshi higher secondary students in mainstream schools to determine the current practices of PT-E phenomenon, that had been motivated them to be enrolled in private tutoring sessions besides their formal schoolings. Each participant
\end{abstract}




\section{Macrothink}

Journal of Studies in Education

ISSN 2162-6952

2018, Vol. 8, No. 4

participated in one-to-one in-depth semi-structured interview. From nine verbatim transcripts 237 significant statements and four themes were emerged. The data represented that academic credentials, peer pressure, role of English in Bangladesh and parental involvement seem to be highly influential factors that influence school students to participate in PT-E.

Keywords: Private Tutoring in English, lived experience, shadow education, societal factors and Bangladesh. 


\section{Introduction}

Private tutoring (PT) has become a global phenomenon since the last quarter of the twentieth century (Bray, 2013; Bray \& Lykins, 2012; Dang \& Rogers, 2008a; Mazawi, Sultana, \& Bray, 2013; Song, Park, \& Sang, 2013). It is mostly common in Asia, particularly in East Asia (e.g., Japan, China, Singapore, Hong Kong and South Korea). In Hong Kong, for example, a survey of 898 secondary students found that $72.5 \%$ in lower secondary had received private tutoring, while the proportions in middle and senior secondary school were $81.9 \%$ and $85.5 \%$, respectively (Ngai \& Cheung, 2010). In Japan, a 2008 survey found that $72.5 \%$ middle school students and 60.5\% high school students received private tutoring (Kim \& Park, 2010). Though it is common in East Asia nations, the issue of private tutoring has widely been discussed in Africa, Europe, and North America (Ireson \& Rushforth, 2011; Jheng, 2015).

Private tutoring in English (PT-E), as a subfield of private tutoring (PT), has recently received attention from researchers (Hamid, Sussex, \& Khan, 2009; K. Yung, 2014). For instance, in a recent study in Hong Kong, Bray (2013) shows that the proportion of secondary students (71\%) taking private tutoring in English was much higher than that of mathematics $(58 \%)$ and Chinese (39\%). Similar insights were generated by few more studies on PT in Asian and East Asian nations (Hamid \& Baldauf Jr, 2011; Lee 2010; S. J. Park \& Abelmann, 2004). Furthermore, there are some recent studies that focus on the role of PT-E and students' academic performance in relation to test scores in English along with the test scores in other subjects that are used as measures of academic achievement (Hyunjoon Park, Byun, \& Kim, 2011). For example, Kang (2007) shows that there is a significant improvement in grades resulting from expenditure on private tutoring in English among South Korean students, controlling for teacher assessed initial ability, hours of self-study, and family characteristics.

Aim of the study

Previous research on private tutoring has drawn attention to the relations of social, economic and educational forces (Bray \& Kobakhidze, 2014; Dang \& Rogers, 2008b; De Silva, 2015; Jung \& Lee, 2010), and shed light mainly on the system as a whole ( at the macro-level) rather than on the pedagogies and individual aspects ( at the micro-level) (W. h. Yung, 2011).

Therefore, the present article aims to address this research gap by focusing on English teaching and classroom practices ( at the micro-level) in the context of the 'out of classroom practice' of private tutoring among Bangladeshi higher secondary students who participate in private tutoring in English (PT-E). It attempts to examine how their experiences have been influenced by private tutoring in English (PT-E). Thus, this article has been guided by the research question as below: what societal factors influence the lived experiences of Bangladeshi higher secondary students in private tutoring sessions in English?

In Bangladesh, Private tutoring in English (PT-E) is perceived as playing a very significant role to get academic accomplishment and English proficiency, which is to some extent different from its implementation in East Asia, Europe, or North America (Hamid et al., 2009). In fact, where over one-third of the 160 million citizens do not have formal literacy (Hamid \& Honan, 2012), both PT and PT-E have been dominant in all levels of education in Bangladesh (Hamid 
et al., 2009; Nath, 2008). But, research on private tutoring of English (PT-E) is scanty in Bangladesh even though English is seen as a crucial linguistic capital or cultural capital (Bourdieu \& Passeron, 1977). As a result, the present study has the intention to fill up this research gap by explaining the societal aspects that influence higher secondary students to take up PT-E in Bangladesh along with their mainstream schoolings.

Private Tutoring in English (PT-E) and societal factors

Research on PT-E has indicated that participation in tutoring enhances students' academic outcomes and boosts their desired academic credentials (Lee 2010; S. J. Park \& Abelmann, 2004). For instance, Kang (2007), in his study, indicates a significant improvement in grades resulting from expenditure on tutoring among South Korean students, controlling for teacher assessed initial ability, hours of self-study, and family characteristics. Fewer such studies have been carried out in European countries too. For example, the study in England, USA, Canada Greece, Germany, and Turkey indicates some benefits regarding academic result ( credentials) associated with PT or PT-E (Byun \& Park, 2012). In the German context, Mischo and Haag (2002) have found that PT-E is associated with improved academic outcomes across all subjects (Math, English, Latin, and French), as well as improved self-confidence and reduced test anxiety. The study compares pairs of participants and non-participants match in terms of prior school marks, but no other controls are used.

Furthermore, in many societies, historically, wealthy elite's parents take private tutors for their children as they consider private tutoring as a direct investment to boost children's academic skills and knowledge. In these contexts, parents are motivated by the prospect that spending money in private tutoring may help children to gain better academic success. many recent studies have shown that wealthier families are more likely to purchase tutoring and to engage in more elaborate forms of it (Kim \& Lee, 2010; Stevenson \& Baker, 1992). For this reason, many recent studies reveal that adoring parents have created private tutoring a major business in many part of the world (Bray, 2014; Bray \& Kobakhidze, 2014; Krarup \& Munk, 2014; Mazawi et al., 2013; H. Park, Byun, \& Kim, 2010; Zhang \& Bray, 2013) because of facing diffusive pressures of credential competition for their children as there is no an equivalent educational alternative. For instance, parental investment in private tutoring in wealthier East Asian countries like Korea, Japan, Hong Kong, and Taiwan amounts to billions of dollars annually (Bray, 2001; Lee, 2007; Stevenson \& Baker, 1992).

Thus, the parental involvement in PT-E seems to result from the parents' beliefs and hopes of tutoring that can assure their children a higher social status by helping them to be admitted into prestigious universities through higher achievement and so higher career establishment (Baker, Akiba, LeTendre, \& Wiseman, 2001; Bray \& Silova, 2006; Lee, 2007). Another contributing factor to this growth seems to come from the fear that their children would be left behind without PT or PT-E.

\section{The study Design}

According to Marshall and Rossman (1999), phenomenological methodology enables researchers to understand the meaning that participants attribute to their actions, thoughts, 
feelings, beliefs, values, and assumptive worlds that assist to assess the 'essence' of phenomenon. So, by selecting a phenomenological qualitative research design, the present article attempts a micro level study, i.e. a small scale, in-depth investigation, to ensure a rich description of lived experiences of PT-E phenomenon. Therefore, using small scale phenomenological qualitative method for the present research represents an innovative departure, adds a new, previously ignored perspective on the lived experiences of participants in PT-E, from previous researches which have used large scale, macro-level and quantitative investigations.

\section{Participants}

Researchers selected, for in-depth interviews, higher secondary schools (Note 1) students who had been taking up private tutoring in English (PT-E) and had at least four to seven years of experiences on it. By using careful sampling, researchers chose nine students to capture the lived experiences on PT-E phenomenon. Two different regional areas were identified to get the different background among the participants based on urban (metropolitan city) and rural (sub-district) area in Bangladesh (see figure 3.1). The first site of the present study was in Rangpur, a regional metropolitan city in the northern Bangladesh; and the second one was in Rajarhat, a rural sub-district under Kurigram district, located in the northern region of the country. After selecting the study sites, both government and non-government schools were selected within these two sites. Both types of schools follow the national curriculum and use Bangla language as a medium of instruction.

Besides the regional and school variations, the chosen students were identified among students who had been participating to different types of private tutoring in English (PT-E). These types of tutoring had been divided into three kinds. 'One to one private tutoring' refers to tutoring conducted between one tutor and one tutee. 'Small-group private tutoring' refers to tutoring conducted between one tutor and 2 to 9 students in a group. Tutoring with 10 or more students in a group was considered 'coaching' refers to large-group tutoring conducted in large-scale

Finally, along with the in-depth interview, out of nine students, three students (e.g., considering of their types of schools, tutoring and locations) were identified for the case studies to get more insight into the lived experiences of PT-E participants. Table 3.1 presents the profile of the nine participants who were selected for the study.

Data Analysis

The study used a face to face semi-structured formal interview for in-depth understanding of PT-E phenomena. All interviews were audio-recorded and transcribed verbatim as soon as possible following the interview. Once transcription was finished, data was analyzed with the assistance of Nvivo 10, a qualitative software program. The Nvivo 10 software program assisted researchers in coding themes, managing and analyzing unstructured information.

Initially, the process began with reading through the written transcripts several times to capture initial impression. After getting initial impression, the process of coding was applied immediately. To assist in the coding process a log was maintained through the process. Then from each transcript, significant phrases or sentences that pertained directly to the lived 
experience of PT-E was identified. That is, the open coding process was assigned to sort out various aspects of the data that had been retrieved to give the answer of the research question to refine a list of codes that identified the major ideas and perspectives through themes. These themes were then become the findings of the study.

\section{Findings}

Data was analyzed to validate the research question of the study, 237 significant statements (i.e., significant phrases or sentences that pertained directly to the lived experience of PT-E participants) were identified from nine verbatim transcripts of interviewees. As of 237 significant statements, four themes are originated from the analysis of the participants' responses to the interview questions (see Appendix A). These include: (1) PT-E response to academic credentials, (2) role of in English in Bangladesh, (3) peer pressure and (4) parental investment.

Each theme deals with necessary validation of societal issues of PT-E that motivate them to engage in PT-E. For instance, in the theme 1, interviewees emphasize on the social value of academic credentials classifying PT-E is "very important" to earn their desired academic credentials. Otherwise, they cannot do "the best for future career". Similarly, students also influence to involve in PT-E thinking of the significant role of English in Bangladesh, described in the theme 2. More clearly, considering the role of English language in Bangladeshi society, participants need to earn their expected English skills which are difficult to develop only through school English teaching. Finally, not only peer pressure but also parental involvement in their children educations motivates students to take up PT-E, discussed in the theme 3 and 4 respectively. In fact, the demand of English language in Bangladeshi society just likes any other commercial product. The detailed findings of these themes are analysed below.

Theme 1: PT-E response to Academic credentials. In this theme, participants, irrespective their locations (urban and rural) and type of schools (government and non-government) as well as tutoring (one-to-one, small group and large group), spotlighted the value of academic credentials that influenced them a lot to participate in PT-E. The significance of academic credentials pictured in the description of an urban non-government school participant, undergoing PT-E for 6 years of experience, summarized his coping:

As a student, now I am not interested about the learning, but I want to do the best result in the public exam. In our society, everybody cares of my A+ [excellent grade] result rather my learning. There is no value for learning...... everyone wants the best result. So, I also want A+ result.

Another urban non-government school student, taking up PT-E from grade 5, stated the same view and articulated:

Yes, sometimes they [school teachers] advise me to take up private tutoring because it is difficult to do better in future if I do not do well in the public examination. So my certificate with a good grade is very important in future 
The singleness of purpose is further illustrated in the statement of a rural public school interviewee, having 7 years experience of PT-E, "I never emphasize on the education rather emphasize on the exam grade [certificate]. They [students] do not have anything in the brain but they are getting A+ [excellent grade] in the exam and coaching helps to achieve it." This was also evident in a description of a rural student, having 5 year experiences, by upholding his future result: "I am taking up PT-E because I have a plan to do the best in my upcoming public exam and I am expecting the very good grade by taking up PT-E."

A sense of social value of academic qualifications was predominant among the participants (both urban and rural areas). An urban student, coming from a middle class educated family, noted, "In Bangladesh the importance of examination result is very important that highly motivated me to take up PT-E." Another rural non-government school student, coming from a lower middle class education family, described his opinion by saying, "Nowadays result is very important." A rural student, coming from a poor farmer family and taking PT-E in a coaching centre, reported, "The present education system emphasizes on the exam result so much." Likewise, a government school student, involved in PT-E from grade 7, stated, "Actually result is so important that parents only motivate to do the best in the exam result."

Thus, it can be concluded that interviewees, irrespective their locations, schools and tutoring, have the same purpose of undergoing PT-E so that they can earn their desire credentials.

Theme 2: Role of English in Bangladesh. In this theme, participants, irrespective their locations and types of school and tutoring, focused on the role of English in Bangladesh as a significant factor to take up PT-E. Responding spontaneously and quickly, some described the role of English in Bangladeshi society influences them to participate in PT-E. A rural non-government school student, taking up PT-E in a small group from grade 6 , noted:

English is important language beside Bangle in Bangladesh and in many ways it is the essential language in our country. It is our $2^{\text {nd }}$ language [particularly in education sector]. Not only it is the required language to pass the exam but also it is an important language in every sector. Therefore, I need to take up PT-E to acquire necessary skills on it.

Similarly, Another urban public school student, taking up one-to one PT-E from grade 5, emphasized: "English is very important in our [Bangladesh] society." One more student from urban school expressed the same view and concluded it as, "I am learning English that helps for my future." So, as participants felt that English skills had been considering highly demandable skills in Bangladesh and only school English teaching is not enough to achieve the required skills in English. For this reason, they preferred to participate in PT-E to gain the "necessary skills" in English.

Consistently, the lived experiences of participants (both urban and rural) revealed that they usually motivated for learning English, although for various purposes, not for their examination results, but rather for thinking of the value of English in Bangladeshi society. For example, a rural student, taking up PT-E in a coaching centre from grade 7, described, "Now in Bangladesh it is necessary to know English well for future status, career etc, which motivate 
me to take up PT-E.” Another one, studying in an urban non-government school, described it as, "I need private tutoring in English because English is very important in every sector. English is necessary to get job and do the higher study." So, an urban student studying a non-government school, having 6 years PT-E experience, summarized:

Getting job with handsome salary, English gets the top priority. Moreover, especially in higher education, English is very important as and textbook at the university level is written in English and the medium of instruction is English So I emphasize on PT-E at school level to learn English more.

As a final point, the existing role of English is fundamentally considered one of the most important skills that interviewees need for their future establishment in Bangladeshi society. That is why, participants emphasize the development of English skills as a long-lasting disposition of the individual' mind.

Theme 3: Peer pressure. In this theme, all 11 participants provided strong endorsement of the role of peer pressure to participate in PT-E. This was evident in a statement of an urban government school student, having 7 years of experience, as:

I also motivate to take up PT-E because my friends have been taking up PT-E.... means..... He often talked about his PT-E experience and expressed his satisfaction about PT-E tutor teaching techniques that are very good to do better in the public exam result, so I feel that I should go to take up PT-E. Moreover, I also see that some of my friends are always very good in the class due to having the PT-E."

An urban non-government school student, taking up PT-E from grade 5, expressed it as "I see that my friends are taking up PT-E; I take decision to take up PT-E." Another one asserted, "I get information and inspiration to take up private tutoring from my friends and senior brother."

Furthermore, more students had been taking up PT-E as they felt that everybody involved in it. It was evident in the following description of an urban student studying in a public: "It is true that I am not only student who is taking PT-E rather it has been taken almost every student in Bangladesh." Another rural student, having 5 years experience of PT-E stated, "I also motivate to take PT because my friends take up PT-E"

Finally, interviewees (both urban and rural) concluded that peer pressure forced them to engage in PT-E. Moreover, if they did not participate in PT-E, they would be out of the common circle where everybody was involved in PT-E practice. An interviewee from a public school, taking up PT-E from grade 5, posited it as "my friends' attitude towards PT-E is very much positive about private tutoring because they believe I need private tutoring for doing well in my public exam." A rural student expressed it more clearly and pointed it as "They [friends] said why you are not taking PT-E when we [other friends] are taking up it. As they are taking up PT you should take up it."

Theme 4: Parental involvement. In this theme, all participants, irrespective of location and types of school and tutoring, felt that they had been getting positive assistances from their 
parents as their beliefs were centred to think about their children public examination success and the better future career. So, parents believed that PT-E was needed to do better in the examination grades. For instance, this was evidenced in an opinion of an urban public school student, having 7 years of experience as:

My Parents always expect that I should do well in my public exam. For this reason, they emphasize on the importance of taking up PT-E and their attitudes are very much positive.

Another urban public school student, taking up one-to-one PT-E from grade 5, stated it as, "When I did not do well in the school annual exam, they [parents] asked me to take PT -E because they believed due to PT-E tutor; I did not do well in the exam result." So, He also further concluded: "......... my parents motivate me to take up PT-E when I did not do good result in school exam."

Like urban students, rural participants also expressed the same view. This was evidenced in a description of a rural non-government school student, taking up PT-E in a coaching center from grade 6 , stated it as:

My parents' attitude is........hmmm... If I do well in the exam, my parents consider that my PT tutor is good. They never ask about school class learning. They always give priority to PT-E. Even, sometimes they call to my PT-E tutor to take information about my learning whereas they never ask anything to my school teacher.

Another rural government school student, taking up PT-E in a school teacher batch, viewed:

Clearly they [my parents] will be worried. They know that school does not teach well because school classes are not regular. For this reason, when I am taking up PT-E, they feel comfortable about the progress of my study because they think ....... going school as well as taking up PT-E... means.....my study is in the right track. On the other hand, if I do not take up PT-E, they [parents] think that it will be difficult for me to do the best in the exam.

Sometimes, parents, particularly in the urban area, would like to spend more money for their children's PT-E because they believed that it is much more effective way to earn the good result in the public examination than the school teaching. It was evident in a description of an urban non-government urban school student as: "They [parents] do not tell me anything about my private tutoring expenditure rather they encourage me to spend money for my education [private tutoring and other educational expenditure.]" Furthermore, apart from the expectation of examination grades, parents also believed that there was a problem in the school English teaching. An urban government school student noted, "They [parents] know that school classes are not held properly. Particularly, my mother knows that classes are not occurred in the school regularly. So she motivates me to take PT-E."

\section{Case Profiles}

The case profiles of the students can be facilitated to understand the societal aspects of PT-E that influences the lived experiences of Bangladeshi higher secondary students in private tutoring sessions in English. The following three case profiles substantiate the patterned relationships between students who are currently participating in PT-E. 
Case Profile One: an urban non-government student having 7 years experience of PT-E

This participant lives in a central Rangpur which is the metropolitan city in the northern Bangladesh. He has been studying one of the top no-government schools in this city, which is governed by a social welfare organization. Now, the interviewee is the 12th grader studying science section. He has been taking up PT-E from the $5^{\text {th }}$ grade.

Right now he is taking up one-to-one tutoring and he is very positive about those lessons. He asserts that taking private lessons in English is a must for doing well in the examination. He finds PT-E more useful and effective than school English. He has to spend 3000 taka per month for taking up PT-E. As his father is a business man, he has enough money to hire private tutor for his son at home. His mother also encourages him to take up PT-E as she highly emphasizes his academic result and expects that he must do the best in his upcoming public examination. Furthermore, he is generally satisfied with the parental support for his studies. His father buys him books and stationery whenever needed. He also gets regular support for his PT-E tutor, although he expected to take more such lessons.

He takes PT-E at home. His PT-E tutor is his school English teacher too. For this reason, he is very much positive about the tutoring service as he is getting the best friendly environment for preparing the upcoming public examination. However, along with English language tutoring, he takes another three subjects tutoring as he is a science section student. Although English is not his favorite subject, he makes every effort to learn English. He would learn English even if it was not a compulsory school subject. He has high academic self-concept in English. He ranks himself on top of his cohort. He expects A+ in English in the HSC examination and he is confident that he will obtain at least an A. He finds English easy to learn, and has learnt English as much as is taught by the textbook. However, he is not happy with his current level of competence because he says that he can't function in it properly. He wants to improve his English and be able to speak the language fluently.

He likes school very much, but he is not happy with the way English is taught at school. This is due to the teachers' inadequate skills, large class size, expertise and qualifications. He has an average liking for English, but he understands its importance for his future studies and for his career. He has set clear goals for his future and his father knows those goals. He is confident that he will be able to reach his academic and career goals in future.

Case Profile two: an urban government student having 5 years experience of PT-E

This student is studying in a public college (government higher secondary school) in Rangpur, the northern metropolitan city in Bangladesh. She comes from village school which is situated in her home district where she had been living with her parents until the10th grade. Now, she is living in a student house near to her campus where her other friends are living too. Her father is a businessman who runs family businesses. Her father had completed high school 
education. Her mother had secondary school qualifications. She is a housewife.

Her parents cannot help her with her studies because they are not living with her. However, they are very conscious of her education needs and will do whatever is needed for her studies. They also know how well she was doing at school. She is fully satisfied with her parents' support. She thinks that she is provided with everything she requires. Her parents played a crucial role in her academic achievement because they made everything available to her including books, stationery, newspapers and private tutors.

She has the mixed experience of private tutoring. When she was in school, she took private tutoring in a village school teacher. Now she has been taking up PT-E in a school teacher batch (small group). Her PT-E tutor is her school teacher too. To engage in PT-E in a batch, she has to pay 500 taka every monthly. Besides English tutoring, she is taking up another two subject tutoring as she is a business section student. According to her view, she is taking up PT-E because of her insufficient school teaching. She is not happy about her classroom instruction. There are huge students in a class (more than 80. For that, she takes up in a small group of students where she finds the positive environment and learns helpful technique to do the best in her upcoming public examination.

Case Profile three: a rural non-government student having 6 years experience of PT-E

The participant has been studying in a non-government college in Rajarhat Upzila under the district of Kurigram. The student comes from farmer family. The financial condition is not good. For this reason, he is taking private tutoring in a coaching center where he takes all subjects besides English. He is a science section student. According to him, He is taking up four subjects private tutoring in a coaching center which is not so much expensive compared to private batch.

The interviewee is a regular school-goer and cannot remember a day when he was absent from school. He likes school because the environment there is better than at home. The school offered opportunities for learning, talking to teachers about studies, associating with classmates and playing games and sports. However, he does not idealize school; it has lots of problems and he was aware of them. He also understands that a rural school like theirs will have those problems, but he is particularly dissatisfied with English teaching at school. He noted that their English teacher was not qualified enough to teach; he also expressed his disappointment that English classes were not held regularly because of teacher absenteeism and weak school administration. He was particularly worried about English because English was hard to him and unlike other subjects he could not manage it on his own. The poor teaching of English at school worried him because he was unable to take help from private lessons in English due to financial reasons. 
His views of English are complex. He is well aware of the role that English will play in his future educational and career expectations. He is eager to learn the language and invests his time and efforts, but he needs help and support in English. The absence of this support and his inability to learn the language has made him develop apparently negative outlook on English. He could not like English as much as he desired because he thinks he has not learnt it that much and he is unable to develop his liking without being able to use it

\section{Discussion}

Societal aspects of PT-E were examined from the participants' subjective perspectives, which are related to the study's research question: What societal aspects influence the lived experiences of Bangladeshi higher secondary students in private tutoring sessions in English? The analysis and interpretation of the phenomenological qualitative data showed that there was an underlying agreement across the perspectives, which endorsed the fact that the participants' lived experiences of PT-E were fundamentally influenced by the societal factors.

First, participants asserted that their academic credentials (theme 1) were substantially influenced by their societal circumstances. Both urban and rural participants observed that schooling was inadequate in ensuring their academic credentials. The present study found that PT-E activities of the secondary students in Bangladesh were centered by their sky-high expectations of academic credentials. It was evident that they seemed to rely on PT-E to believe it as one of the important activities to obtain academic credentials. This finding is consistent with other studies on PT-E has indicated that participation in tutoring enhances students' academic outcomes and boosts their desired academic credentials (Lee 2010; S. J. Park \& Abelmann, 2004).

Second, the findings also revealed a range of other societal issues, such as, the role of English in Bangladesh (theme 2), peer pressure (theme 3) and parental investment ( theme 4) on children education had been influenced students to participate in private tutoring sessions in English besides their mainstream schoolings. Moreover, participants highly motivated by the profitable service of private tutoring, such as, exam tips or shortcut techniques to get academic credentials in the public examination result, as evidenced by their responses to depend on the PT-E. This finding is consistent with other studies on the growing demand of marketable education across the world (Burch, 2009; Verger et al., 2012) Besides the global demand of English, some were also motivated by the role of English in Bangladesh (theme 2) as English is viewed as a language of power and mobility in Bangladesh (Hamid, 2009).

Consistent with Bray and Kwo (2013), theme 4, parental investment of PT-E, emerged as parents believed that PT-E was needed to do better in the public exam and to earn their preferred academic credentials. Moreover, this finding is consistent with few recent studies regarding parental involvement and investment in private tutoring making PT as a profitable service (Bray \& Kobakhidze, 2014; Chan \& Bray, 2014; Dawson, 2010; Zhang \& Bray, 2013).

Although the findings indicate a role of peer pressure (theme 3), this pressure or competition is probably more relevant at the societal level than at the level of individual students. In a world 
of increasing competition for access to English, education and employment (Erling, Seargeant, $\&$ Solly, 2014), parents and their offspring cannot afford to lose. Therefore, PT-E is taken as a parental strategy, an investment in children's cultural capital development (K. M. Kim \& Park, 2012), "as a form of protection against losing" (Bray, 2013, p. 27). The endorsement of PT-E by students can be understood from the meeting of the opposite forces at the global and local level the global competition for shrinking opportunities such as places for education and employment and the local failure of formal schooling in equipping students with English language proficiency.

Finally, the case profiles of the students revealed how their English learning and academic experience were situated in their social worlds. Specifically, the study showed how the students' English learning experience cannot be alienated from their views of schools and education, their attitudes and motivations, their desires for a better future on the one hand and the uncertainty of their future on the other, the practice of PT-E in the context of poor teaching of English at school, and the lack of learning opportunities in the community, their parental investment and their perceptions of the influence. Their case profiles warrant a holistic approach, since neither an exclusive focus on structure nor on agency is adequate in drawing a comprehensive picture of their academic experience and English achievement. In other words, there is a need to consider their lives in family and society, the extent of their access to educational capital and other resources, their lived experiences, their views of school and schooling in English and their future aspirations if we want to develop a deeper and wider understanding of their English learning outcomes (Cooke, 2006).

\section{Conclusion}

The finding of the study scrutinizes this question of how the societal factors of PT-E motivate students to involve in PT-E. In this study, the societal issues of Bangladeshi society are viewed as a south Asian country. It is markedly different in many aspects from the western society in terms of its education system, school entry and symbolic and cultural meanings of English language. That is, colonial practices of English still prevail in its power over EFL teaching and learning practices. Hence, peer pressure and parental involvement have strong influence in the educational decision making process in Bangladesh.

\section{Notes}

Note 1. In Bangladesh, school has three levels: primary, secondary and higher level. Generally, higher secondary schools are called 'college'. Usually, college teaches $11^{\text {th }}$ and $12^{\text {th }}$ grade students.

\section{References}

Baker, Akiba, M., LeTendre, G. K., \& Wiseman, A. W. (2001). Worldwide shadow education: Outside-school learning, institutional quality of schooling, and cross-national mathematics achievement. Educational Evaluation and Policy Analysis, 23(1), 1-17. https://doi.org/10.3102/01623737023001001 
Bourdieu, P., \& Passeron, J.-C. (1977). Reproduction in education, culture and society. Trans. Nice, R. London: Sage.

Bray, M. (2001). Out-of-School Supplementary Tutoring. Childhood Education, 77(6), 360-366. https://doi.org/10.1080/00094056.2001.10521671

Bray, M. (2013). Shadow Education: Comparative Perspectives on the Expansion and Implications of Private Supplementary Tutoring. Procedia - Social and Behavioral Sciences, 77, 412-420. https://doi.org/10.1016/j.sbspro.2013.03.096

Bray, M. (2014). The impact of shadow education on student academic achievement: Why the research is inconclusive and what can be done about it. Asia Pacific Education Review, 15(3), 381-389. https://doi.org/10.1007/s12564-014-9326-9

Bray, M., \& Kobakhidze, M. N. (2014). The Global Spread of Shadow Education Qualities of Education in a Globalised World (pp. 185-200): Springer.

Bray, M., \& Kwo, O. (2013). Behind the façade of fee-free education: shadow education and its implications for social justice. Oxford Review of Education, 39(4), 480-497. https://doi.org/10.1080/03054985.2013.821852

Bray, M., \& Lykins, C. R. (2012). Shadow Education: Private Supplementary Tutoring and Its Implications for Policy Makers in Asia (Vietnamese translation): Asian Development Bank \& Comparative Education Research Centre, Faculty of Education, The University of Hong Kong.

Bray, M., \& Silova, I. (2006). The private tutoring phenomenon: International patterns and perspectives. Education in a hidden marketplace: Monitoring of private tutoring, 27.

Burch, P. (2009). Hidden markets: The new education privatization: Routledge. https://doi.org/10.4324/9780203883945

Byun, S. Y., \& Park, H. (2012). The Academic Success of East Asian American Youth: The Role of Shadow Education. Sociol Educ, 85(1), 40-60. https://doi.org/10.1177/0038040711417009

Chan, C., \& Bray, M. (2014). Marketized private tutoring as a supplement to regular schooling: Liberal Studies and the shadow sector in Hong Kong secondary education. Journal of Curriculum Studies, 46(3), 361-388. https://doi.org/10.1080/00220272.2014.883553

Cooke, M. (2006). "When I wake up I dream of electricity": The lives, aspirations and 'needs' of Adult ESOL learners. Linguistics and Education, 17(1), 56-73. https://doi.org/10.1016/j.linged.2006.08.010

Dang, H.-A., \& Rogers, F. H. (2008a). The Growing Phenomenon of Private Tutoring: Does It Deepen Human Capital, Widen Inequalities, or Waste Resources? The World Bank Research Observer, 23(2), 161-200. https://doi.org/10.1093/wbro/lkn004

Dang, H.-A., \& Rogers, F. H. (2008b). How to Interpret the Growing Phenomenon of Private Tutoring: Human Capital Deepening, Inequality Increasing, or Waste of Resources? World Bank Policy Research Working Paper Series, Vol. 
Dawson, W. (2010). Private tutoring and mass schooling in East Asia: reflections of inequality in Japan, South Korea, and Cambodia. Asia Pacific Education Review, 11(1), 14-24. https://doi.org/10.1007/s12564-009-9058-4

De Silva, W. A. (2015). Shadow education: private supplementary tutoring and its implications for policy makers in Asia. Compare: A Journal of Comparative and International Education, 45(1), 176-179. https://doi.org/10.1080/03057925.2014.972719

Erling, E. J., Seargeant, P., \& Solly, M. (2014). English in rural Bangladesh. English Today, 30(04), 15-21. https://doi.org/10.1017/S0266078414000352

Hamid, M. O. (2009). Language policy, culture, and identity in Asian contexts, by A. Tsui and J. Tollefson: (Eds.).(2007). Mahwah, NJ: Lawrence Erlbaum Associates, Inc.,pp. 283.

Hamid, M. O., \& Baldauf Jr, R. B. (2011). English and socio-economic disadvantage: learner voices from rural Bangladesh. Language Learning Journal, 39(2), 201-217. https://doi.org/10.1080/09571736.2011.573687

Hamid, M. O., \& Honan, E. (2012). Communicative English in the primary classroom: implications for English-in-education policy and practice in Bangladesh. Language, Culture and Curriculum, 25(2), 139-156. https://doi.org/10.1080/07908318.2012.678854

Hamid, M. O., Sussex, R., \& Khan, A. (2009). Private tutoring in English for secondary school students in Bangladesh. Tesol Quarterly, 43(2), 281-308. https://doi.org/10.1002/j.1545-7249.2009.tb00168.x

Ireson, J., \& Rushforth, K. (2011). Private tutoring at transition points in the English education system: its nature, extent and purpose. Research Papers in Education, 26(1), 1-19. https://doi.org/10.1080/02671520903191170

Jheng, Y.-J. (2015). The influence of private tutoring on middle-class students' use of in-class time in formal schools in Taiwan. International Journal of Educational Development, 40, 1-8. https://doi.org/10.1016/j.ijedudev.2014.11.019

Jung, J. H., \& Lee, K. H. (2010). The determinants of private tutoring participation and attendant expenditures in Korea. Asia Pacific Education Review, 11(2), 159-168. https://doi.org/10.1007/s12564-009-9055-7

Kang, C. (2007). Does money matter? The effect of private educational expenditures on academic performance. National University of Singapore, Department of Economics Working Paper, 704.

Kim, J. H., \& Park, D. (2010). The determinants of demand for private tutoring in South Korea. Asia Pacific Education Review, 11(3), 411-421. https://doi.org/10.1007/s12564-009-9067-3

Kim, K. M., \& Park, D. (2012). Impacts of urban economic factors on private tutoring industry. Asia Pacific Education Review, 13(2), 273-280. https://doi.org/10.1007/s12564-011-9192-7 
Krarup, T., \& Munk, M. D. (2014). Field theory in cultural capital studies of educational attainment. British Journal of Sociology of Education, 1-19. https://doi.org/10.1080/01425692.2014.969398

Lee, B. (2010). The pre-university English-educational background of college freshmen in a foreign language program: a tale of diverse private education and English proficiency. Asia Pacific Education Review, 11(1), 69-82. https://doi.org/10.1007/s12564-010-9079-z

Lee, J. (2007). Two worlds of private tutoring: The prevalence and causes of after-school mathematics tutoring in Korea and the United States. The Teachers College Record, 109(5), 1207-1234.

Marshall, C., \& Rossman, G. (1999). Designing qualitative research . 1999: Thousand Oaks, CA: Sage Publications.

Mazawi, A. E., Sultana, R. G., \& Bray, M. (2013). Beyond shadows Private tutoring across the Mediterranean (pp. 205-216): Springer. https://doi.org/10.1007/978-94-6209-237-2_13

Mischo, C., \& Haag, L. (2002). Expansion and effectiveness of private tutoring. European Journal of Psychology of Education, 17(3), 263-273. https://doi.org/10.1007/BF03173536

Nath, S. R. (2008). Private supplementary tutoring among primary students in Bangladesh. Educational Studies, 34(1), 55-72. https://doi.org/10.1080/03055690701785285

Ngai, A., \& Cheung, S. (2010). Students' participation in private tuition. Youth Poll Series(188).

Park, H., Byun, S.-y., \& Kim, K.-k. (2011). Parental involvement and students' cognitive outcomes in Korea focusing on private tutoring. Sociology of education, 84(1), 3-22. https://doi.org/10.1177/0038040710392719

Park, H., Byun, S. y., \& Kim, K. k. (2010). Parental Involvement and Students' Cognitive Outcomes in Korea: Focusing on Private Tutoring. Sociology of education, 84(1), 3-22. https://doi.org/10.1177/0038040710392719

Park, S. J., \& Abelmann, N. (2004). Class and cosmopolitan striving: Mothers' management of English education in South Korea. Anthropological Quarterly, 77(4), 645-672. https://doi.org/10.1353/anq.2004.0063

Song, K.-O., Park, H.-J., \& Sang, K.-A. (2013). A cross-national analysis of the student-and school-level factors affecting the demand for private tutoring. Asia Pacific Education Review, 14(2), 125-139. https://doi.org/10.1007/s12564-012-9236-7

Stevenson, D. L., \& Baker, D. P. (1992). Shadow education and allocation in formal schooling: Transition to university in Japan. American Journal of Sociology, 1639-1657. https://doi.org/10.1086/229942

Verger, A. L., Robertson, S., Robertson, S., Mundy, K., Verger, A., \& Menashy, F. (2012). The GATS game-changer: International trade regulation and the constitution of a global education 


\section{Macrothink}

Journal of Studies in Education

ISSN 2162-6952 2018, Vol. 8, No. 4

marketplace. Public private partnerships in education: New actors and modes of governance in a globalizing world, 104.

Yung, K. (2014). Learning English in the Shadows: Understanding Chinese Learners' Experiences of Private Tutoring. Tesol Quarterly.

Yung, W. h. (2011). Shadow education in Hong Kong: the experienceof learners of English. The University of Hong Kong (Pokfulam, Hong Kong). https://doi.org/10.5353/th_b4696035

Zhang, W., \& Bray, M. (2013). Researching supplementary education: Plans, realities, and lessons from fieldwork in China. Out of the shadows: The global intensification of supplementary education (International Perspectives on Education and Society, Volume 22), 67-94. https://doi.org/10.1108/S1479-3679(2013)0000022002 